ME 06/075 - Full paper

\title{
Mt-DNA phylogeography of Lissotriton boscai (Caudata, Salamandridae): evidence for old, multiple refugia in an Iberian endemic
}

5

6

1: Museo Nacional de Ciencias Naturales, C.S.I.C., c/ José Gutiérrez Abascal, 2. 28006 Madrid, Spain. 2 (present address): Museum of Vertebrate Zoology, University of California, Berkeley, 3101 Valley Life Sciences Building. 94720 Berkeley, California, USA.

3: CIBIO, Centro de Investigação em Biodiversidade e recursos Genéticos. Campus Agrário de Vairão, 4485-661 Vairão, Portugal.

Key words: Phylogeography, Bayesian Skyline Plots, Nested Clade Analysis, mitochondrial DNA, Lissotriton boscai, Iberian Peninsula

Corresponding author: Iñigo Martínez-Solano. Museum of Vertebrate Zoology, University of California, Berkeley. 3101 Valley Life Sciences Building, 94720 Berkeley, California, USA. Fax: (1) 510643 8238. E-mail: inigomsolano@berkeley.edu

Running title: Phylogeography of Lissotriton boscai 


\section{Abstract}

45

46

47

48

49

50

51

52

53

54

55

56

57

58

59

60

61

62

63

64

65

66

67

68

69

70

75

76
Climatic fluctuations during the Pleistocene had an important effect on the distribution of flora and fauna in the Northern hemisphere. In Europe, southern peninsulas served as refugia during cold periods, from which formerly glaciated areas were recolonized during interglacial periods. Previous studies have revealed that within each of the main refugial areas, intraspecific lineages exhibited differential responses to climatic changes, often surviving in distinct, allopatric local refugia. We analyzed variability in two mitochondrial markers (nad4 and control region, $\approx 1.4 \mathrm{~kb}$ ) in 103 individuals from 66 locations representing the entire distribution of $L$. boscai, a newt endemic to the western Iberian Peninsula. We inferred the evolutionary history of the species through phylogenetic, phylogeographic and historical demographic analyses. The results revealed unexpected, deep levels of geographically structured genetic variability. We identified two main evolutionary lineages (A and B) within L. boscai, each containing three well-supported clades (clades A1-A3 and B1-B3). We estimated that the first historical split involved populations from central-southwestern coastal Portugal (lineage $\mathrm{B}$ ) and the ancestor of all the remaining populations (lineage A) around 5.8 million years ago (Mya). Both lineages were subsequently fragmented into different population groups (clades A1-A3 and B1B3) between 2.5-1.2 Mya, probably in response to climatic changes during the Plio-Pleistocene. We inferred the phylogeographic and demographic processes that have shaped the genetic structure and the current distribution of L. boscai with nested clade analysis (NCA) and Bayesian Skyline plots (BSP). According to NCA, at lower hierarchical levels within each of the main mt-DNA lineages the patterns observed suggest restricted gene flow with isolation by distance, whereas at higher levels the clades exhibit signatures of contiguous range expansion. The BSP show that all lineages underwent recent bottlenecks (around 75-50 Kya), which were followed by demographic expansions. The significant genetic structure found is consistent with long-term survival of populations in different allopatric refugia, supporting the "refugia within refugia" scenario proposed for southern European peninsulas. The comparison of our results with patterns observed in other co-distributed species highlights the relevance and generality of the "refugia within refugia" scenario for the Iberian herpetofauna and suggests that Mediterranean refuges may have had more relevance than currently acknowledged. We briefly discuss the taxonomic and conservation implications of our results. 
102

103

104

105

106

107

108

109

110

111

112

113

114

115

116

117

118

119

120

\section{Introduction}

The range of a species is determined by ecological requirements and historical factors. Amongst the latter, climatic oscillations through geological time are one of the most important in determining the current distribution of species. For instance, climatic fluctuations during the Pleistocene have had an important effect on the distribution of flora and fauna in the Northern Hemisphere (Hewitt 1999, 2001). In Europe, southern peninsulas have served as refugia during cold periods, from which formerly glaciated areas were recolonized during interglacial periods (Taberlet et al., 1998). However, recent evidence is challenging the pervasiveness of this "Pleistocenic Southern Refuge" scenario, revealing more complex evolutionary histories for many taxa. For instance, in some species genetic differentiation among lineages predates Quaternary glaciations (e.g. Lenk et al., 1999 -Emys orbicularis-; Pidancier et al., 2003 -Rana temporaria-; Babik et al., 2004 -Rana arvalis-). In addition, southern peninsulas were not the only glacial "hot spot" refugia, but other "cryptic" refugial areas have been identified in central Europe (e.g.. Stewart \& Lister, 2001; Schmitt \& Seitz, 2001; Jaarola \& Searle, 2002; Haynes et al., 2003; Sommer \& Benecke, 2004; Babik et al., 2005; Deffontaine et al., 2005; Nieberding et al., 2005). Furthermore, recent studies point out that phylogeographic patterns and processes in species currently occupying the same refugial areas do not always match. Some general recolonization routes from southern refugia have been identified, as well as suture zones where differentiated lineages that were isolated in different refugia meet and occasionally hybridize (Hewitt, 1996; Taberlet et al., 1998). However, the recolonization process is usually driven by species-specific responses to climatic changes, giving rise to highly dynamic community assemblages through geological time (Weider et al., 1999; Stehlik, 2003; Michaux et al., 2005). Furthermore, numerous studies are now revealing that within each of the main refugial areas, intraspecific lineages also exhibited differential responses to climatic changes, often surviving in distinct, allopatric local refugia and exhibiting independent evolutionary histories (Branco et al., 2000; Soranzo et al., 2000; GarcíaParís et al., 2003).

This "refugia within refugia" scenario (Gómez \& Lunt, in press) has important implications for our understanding of the dynamics of postglacial recolonization and current distribution of the European biota. On a broader scale, in the case of widespread species on which most studies have focused so far, because a detailed knowledge of phylogeographic patterns within refugial areas is crucial for deriving robust inferences about the evolutionary history of species at a continental scale (Gómez \& Lunt, in press). On a finer scale, because the succession of events of population fragmentation and subsequent formation of areas of secondary contact and intermixing of populations were particularly frequent within the main refugial areas (e.g. Sequeira et al., 2005). Accordingly, these areas are specially suited for studies focusing on the interface between population differentiation and speciation.

The Iberian Peninsula was one the main refugial areas in southern Europe during the climatic oscillations in the Pleistocene. The climatic, geological and physiographic heterogeneity in this region probably favoured the existence of different refugia on which very different types of habitats allowed the survival of complex and diverse natural communities. This is reflected for example in the complex evolutionary histories exhibited by the dominant vegetation types across the Iberian Peninsula (see Gómez \& Lunt, in press, and references cited therein). 
This heterogeneity is reflected also in the Iberian herpetofauna, which comprises a mixture of species with a wider European distribution coexisting with "true" Iberian endemics. Amongst the latter, a group of species is restricted to the Western half of the Iberian Peninsula, corresponding to the deciduous forest refugial areas during the last glacial maximum (Zagwijn, 1992). Some of these have been previously studied from a phylogeographic perspective (Lacerta schreiberi, Paulo et al., 2001, 2002; Chioglossa lusitanica, Alexandrino et al., 2000; Discoglossus galganoi, Martínez-Solano, 2004). These studies have revealed the existence of multiple Atlantic refugia within the Iberian Peninsula, suggesting a long history of persistence of populations across geological cycles.

Lissotriton boscai (Lataste, 1879) (Caudata, Salamandridae) is an Iberian endemic newt distributed through most of the western half of the peninsula, including a wide variety of habitats from the drier Mediterranean climates to the more humid Atlantic regions (Fig. 1A; Díaz-Paniagua, 2002). It is considered a morphologically and genetically uniform species (García-París et al., 2004), although some studies have described variations in karyological (Herrero, 1991) and morphometric characters (Malkmus, 1981; Díaz-Paniagua \& Mateo, 1999; Malkmus, 2004). The small distribution range and the apparent morphological homogeneity could thus be the consequence of a process of glacial contraction (refuge), followed by a genetic bottleneck, and a limited post-glacial recolonization. If this were the case, we would expect relatively shallow levels of genetic differentiation between intraspecific lineages, as exhibited by other species (see refs. above).

In this paper, we analyze the variability in two mitochondrial markers (NADH subunit 4-nad4and the control region, $\approx 1.4 \mathrm{~kb}$ ) in 103 individuals from the entire range of distribution of the species. The results reveal unexpected, deep levels of geographically structured genetic variability. The data obtained allow us (i) to identify the main evolutionary lineages or clades within L. boscai; (ii) to estimate time divergences among the different lineages identified; and (iii) to infer the phylogeographic and demographic processes that have shaped the genetic structure and the current distribution of the species. We have inferred the evolutionary history of $L$. boscai through phylogenetic, phylogeographic and historical demographic analyses of the data. The significant genetic structure found is consistent with long-term survival of populations in different allopatric refugia. Thus, the hypothesis of recolonization from a single refugium can be rejected, highlighting the relevance and generality of the "refugia within refugia" scenario for the Iberian herpetofauna. Finally, we compare our results with the observed patterns in co-distributed species, and we discuss the taxonomic and conservation implications that can be drawn from our study.

\section{Materials and Methods}

Sampling design:

We sampled the full range of distribution of $L$. boscai in the Iberian Peninsula. We collected samples from 103 individuals at 66 different locations (Fig. 1A and Table 1). The sampling was designed to maximize the number of locations to capture most of the geographic variation in mt-DNA haplotypes; thus, in most locations only 1-2 individuals were sampled. In some other cases we sequenced up to 4 individuals to assess intrapopulation variability (Table 1).

\section{PCR amplification and sequencing:}


We extracted DNA from small amounts of tissue (muscle from tail tips of adults or larvae) using a standard proteinase K - phenol chloroform protocol (Sambrook et al. 1989). We amplified $\approx 700$ $\mathrm{bp}$ corresponding to part of the nad4 gene and the flanking $t R N A$ His via polymerase chain reaction (PCR) using the primers ND4 and Leu (Arévalo et al., 1994). PCR reactions consisted of 40 cycles with a denaturing temperature of $94^{\circ} \mathrm{C}(1 \mathrm{mn})$, annealing at $54^{\circ} \mathrm{C}(1 \mathrm{mn})$ and extension at $72^{\circ} \mathrm{C}(1 \mathrm{mn})$. Additionally, $\approx 700$ base pairs of the control region were amplified with the primers Pro and Phe (D. Buckley, unpublished, sequences available from the author upon request). PCR conditions were the same than for nad4 except that the annealing temperature was $56^{\circ} \mathrm{C}$. All PCR reactions were performed in a total volume of $25 \mu \mathrm{l}$, including $0.2 \mu \mathrm{l}$ of Taq polymerase $(5 \mathrm{U} / \mathrm{ml}$; Biotools, Madrid, Spain), $0.5 \mu 1$ of BSA $(10 \mathrm{mg} / \mathrm{mL}), 0.5 \mu \mathrm{l}$ of each primer $(10 \mu \mathrm{mol} / 1), 1 \mu \mathrm{l}$ of dNTPs $(10 \mathrm{mmol} / \mathrm{l})$, and $1 \mu \mathrm{lof} \mathrm{MgCl}_{2}$ ( $25 \mathrm{mmol} / \mathrm{l}$ ) plus $2.5 \mu \mathrm{l}$ of a reaction buffer (Biotools). After PCR product purification by ethanol sodium acetate precipitation, samples were cycle-sequenced with the ABI PRISM ${ }^{\circledR} \mathrm{dGTP}$ BigDye $^{\mathrm{TM}}$ Terminator V 3.0 Ready Reaction Cycle Sequencing Kit in 10- $\mu$ l reactions, following the manufacturer's instructions (Applied Biosystems, Foster City, California), with 3.25 pmol of primer, 3 $\mu 1$ of Terminator Ready Reaction Mix, and 5\% dimethyl sulfoxide. The cycling profile for the sequencing reaction consisted of 25 cycles of $10 \mathrm{~s}$ at $96{ }^{\circ} \mathrm{C}, 5 \mathrm{~s}$ at $50{ }^{\circ} \mathrm{C}$, and $4 \mathrm{mn}$ at $60{ }^{\circ} \mathrm{C}$. Forward and reverse sequences were obtained independently. Cycle-sequencing products were purified using MultiScreen filter plates (Millipore, Billerica, Massachusetts) and analyzed on an ABI PRISM 3700 DNA Analyzer (Applied Biosystems).

\section{Phylogenetic analyses:}

For the phylogenetic analyses, we chose as outgroups the species Lissotriton italicus, L. helveticus and Salamandra luschani. Sequences of L. italicus were directly obtained in the laboratory, while the sequences of nad4, tRNA His and the control region for S. luschani and the nad4 and tRNA His for L. helveticus were downloaded from GenBank [accession number for S. luschani: AF154053 (Zardoya \& Meyer 2001); accession number for L. helveticus: AY951649 (Babik et al. 2005)]. E. Recuero kindly supplied the sequence of the control region of L. helveticus.

Sequences were aligned by eye in MacClade v4.08 (Maddison \& Maddison, 2003), generating a data matrix with 106 individuals and 1422 characters (including gaps). Sequences were deposited in GenBank under the Accession numbers listed in Table 1.

We conducted a Maximum Parsimony analysis with PAUP 4.0b10* (Swofford 2002). We performed a Heuristic Search (TBR branch swapping, MULTREES option in effect, and 10 random stepwise addition of taxa), bootstrapping the matrix 100 times to assess the support of the clades recovered. We carried out two different runs, one with an equal weight for transitions and transversions, the second accounting for a differential substitution rate of $3: 1$ for transitions and transversions. This ratio was estimated by Maximum Likelihood (ML) using PAUP 4.0b10*.

We also performed two different phylogenetic analyses based on Bayesian inference using Mr. Bayes v3.1 (Huelsenbeck \& Ronquist 2001; Ronquist \& Huelsenbeck 2003). We determined the bestfitting substitution model for the nucleotide matrix through the Akaike Information Criterion (AIC) implemented in Model-Test 3.7 (Posada \& Crandall 1998). Then, we analyzed the data matrix first as 
an unpartitioned data set. Secondly, we defined five partitions in the data matrix $\left(1^{\text {st }}+2^{\text {nd }}+3^{\text {rd }}\right.$ codon positions for the nad4 + tRNA + control region) in order to account for differences in substitution rates. Default settings were used for the prior distribution in the Bayesian analyses. We ran four Metropolis coupled Monte Carlo Markov chains $\left(\mathrm{MC}^{3}\right)$ for two million generations, sampling every 1000 generations. We discarded 2000 generations as burn in, after checking for stationarity and convergence of the chains with the software Tracer 1.2.1 (Rambaut \& Drummond 2004).

\section{Phylogeographic and historical demographic analyses:}

Distribution of genetic variability is determined by different factors acting at historical (e.g. phylogenetic history, time of divergence between lineages), population (e.g. range expansions, bottlenecks), and organism (e.g. migration rates, mutation rates) levels. Different factors leave distinctive although sometimes overlapping genetic signatures that can be disentangled using appropriate tools. We have explored our data set in three different ways.

First, we analyzed the spatial distribution of genetic variability with a Nested Clade Analysis (NCA, Templeton 1998; 2001). We constructed a statistical parsimony haplotype network (Templeton \& Sing 1992; Templeton et al. 1992) with the program TCS 1.2.1 (Clement et al. 2000). Ambiguous loops in the network were resolved following the recommendations of Pfenninger \& Posada (2002). We grouped haplotypes following a hierarchical nested design, until all haplotypes and clades were grouped into one single main clade (Templeton et al. 1995). Analysis of statistical significance of the relationships between the geographic location of the individuals and their position in the nested haplotype network enabled us to determine the phylogeographic and demographic processes that have shaped the spatial distribution of the observed genetic variability. This part of the analysis was performed with the software GeoDis 2.4 (Posada et al., 2000), permuting the data $10^{6}$ times and interpreting the data with the phylogeographic inference key published in Templeton et al. (1995) and modified in Templeton (2004) (last updated November 11 ${ }^{\text {th }}$ 2005).

Secondly, we explicitly tested the plausibility of an "isolation by distance" (IBD) scenario in the different lineages of $L$. boscai. We performed Mantel's tests (Mantel 1967) to analyze the relationships between genetic and geographic distances between samples and groups of samples. The tests were performed for all the clades recovered in the phylogenetic tree, as well as for the hierarchical nested clades defined in the phylogeographic analysis. The geographic distance matrix between samples $(\mathrm{km})$ was generated with the program GeoDis 2.4 (Posada et al., 2000). The genetic distance matrix (MLcorrected distance) was generated in PAUP 4.0b10* (Swofford 2002). Mantel tests were carried out with the software GenAlEx v6 (Peakall \& Smouse 2001). Data were permuted 999 times to estimate the $95 \%$ upper tail probability of the matrix correlation coefficients. The correlation coefficient (r) varies from -1 to 1 . Probability values $(\mathrm{p}<0.05)$ indicate that correlation coefficients are significantly different from 0 . Values of $r$ represent the "strength" of the correlation between geographic and genetic distances. Rohlf (1993) indicates that for $r<0.7$ (or -0.7 for negative correlations) correlations, even when significantly different from 0 , are weak. When significant associations between geographic and genetic distances were found, we visually analyzed the scatter plots obtained. Under a stepping-stone population model, isolation by distance scenarios reflect an equilibrium between migration, gene flow and genetic drift. At short geographic distances, the effect of migration and gene flow on genetic variability tends to be greater, while over longer geographic distances the homogenizing effect of gene 
flow is counteracted by genetic drift. The different patterns of the plots evidence the relative roles that random genetic drift and gene flow might play in the spatial distribution of the genetic variability (Hutchison \& Templeton 1999).

Finally, we used a Bayesian coalescent-based framework to estimate the demographic history of lineages within $L$. boscai. Coalescence explains how population genetic processes through time have shaped an allelic or haplotypic genealogy (e.g., Hein et al. 2005). Based in coalescence, it is possible to infer several population parameters (e.g., population sizes, mutation rates, migration estimates) from genetic sequence data. In order to recover the demographic history, coalescence methods require an initial demographic model to be specified. We chose as a model the Bayesian Skyline Plot (Drummond et al. 2005). The Bayesian skyline plot fits many different demographic scenarios, minimizing the over-parameterization of the function. However, unlike other skyline methods, the Bayesian skyline plot is coupled with an MCMC sampling procedure, therefore estimating the demographic parameters directly from the sequences and not from a generated genealogy, accounting then for the error associated to phylogenetic reconstruction. The method estimates credibility intervals for the demographic parameters of interest. The Bayesian coalescence-based approach was performed as implemented in the software BEAST 1.3 (Drummond \& Rambaut 2003). We provided the program with a Maximum Likelihood tree generated in PAUP 4.0b10* (Swofford 2002) to initiate the search [GTR + G + I model with four gamma rate categories, selected by Model-Test 3.7 (Posada \& Crandall 1998)]. We ran $10^{6}$ generations. Again, burn in and convergence of the chains were determined by inspection of the data with the program Tracer 1.3. We used the measures of effective sample sizes of each parameter to determine its Bayesian statistical significance (Rambaut \& Drummond 2004). We reran the program several times, optimizing in each run the a priori scale factors of the $a$ priori function.

\section{Divergence time estimates:}

In order to estimate divergence times for the splits between the main mitochondrial lineages recovered, we first tested for clock-like behaviour of the sequences obtained. Sequences were collapsed into haplotypes with the software Collapse 1.2 (available from http://darwin.uvigo.es). We ran a Maximum Likelihood (ML) analysis with a Heuristic Search (TBR branch swapping, MULTREES option in effect, and 10 random stepwise addition of taxa, starting with random trees). We calculated the likelihood scores of the ML tree with and without enforcing a molecular clock. We then performed a likelihood ratio test (LRT) to compare both likelihoods, being the difference not statistically significant under a $\chi^{2}$ test. The molecular clock hypotheses cannot, thus, be rejected for our dataset. Then we generated an ultrametric tree (UPGMA) using the ML distances. The root of the tree, as defined by S. luschani, can be dated at approximately 48 millions of years ago (Mya) (Larson et al. 2003). The most recent common ancestor (MCRA) between Lissotriton helveticus and L. boscai has been dated around 20-22 Mya (Babik et al., 2005). Accordingly, we scaled the branch lengths of the ultrametric tree with these two calibration points to obtain a rough estimate of divergence times between the main mitochondrial lineages recovered.

We also followed a Bayesian coalescent approach to estimate divergence times and their credibility intervals. Again, we used the software BEAST 1.3 (Drummond \& Rambaut 2003). We fed the program with the haplotype ML tree (molecular clock not enforced) to start the search. We specified the age of the root to 48 Mya. We performed different searches specifying different possible 
mutation rates (0.01 mutations/site/Mya; 0.008 mutations/site/Mya; and 0.006 mutations/site/Mya, also combined in Tracer 1.3 the results obtained with the three different mutation rates to estimate divergence times under a more conservative approach. We ran $10^{6}$ generations, following the previous strategy for determining burn in, convergence, stability of the parameters, and optimization procedures.

\section{Results:}

We sequenced a total of 1411 base pairs (nad4: 652bp, tRNA-Hist: $45 \mathrm{bp}$, control region: 714bp) for all of the individuals of the ingroup. We found 52 haplotypes among the 103 sequences. One hundred and ninety-eight sites out of the $1411(14 \%)$ were variable positions, including transitions and transversions in a $3: 1$ proportion. Among the variable sites, 169 nucleotide positions $(12 \%$ of total sites) were parsimony informative (275 characters parsimony informative when outgroups were considered).

\section{Phylogenetic analyses}

In the Maximum Parsimony (MP) analyses, we obtained the same tree topology with the two weighting schemes accounting for different transition / transversion (Ti/Tv) ratios (1:1, trees 894 steps long, Consistency Index: 0.791; 3:1, trees 1554 steps long; Consistency Index: 0.813). Bootstrap values at the basal nodes increased in the $\mathrm{Ti} / \mathrm{Tv}=3: 1$ analysis. In Fig. $1 \mathrm{~B}$, the MP strict consensus tree is represented. The two Bayesian analyses carried out (unpartitioned data set; five partitions) yielded the same topology than the MP analysis. Likelihood scores for the partitioned analysis were slightly higher although statistically not significantly different from the scores for the unpartitioned data set (LRT, data not shown). Posterior probabilities were also similar in both analyses, although two terminal nodes were less supported with the partitioned data set (data not shown). Posterior probabilities are shown in Fig. 1B.

Ingroup sequences cluster into two main mt-DNA lineages (A and $\mathrm{B}$ ), which can be further subdivided into six main clades (A1-A3 and B1-B3, Fig. 1B) with a remarkable concordance with geography (Fig. 1). High bootstrap values and Bayesian posterior probabilities support the clades. Lineage A is widespread in western Spain and most of Portugal, and includes three main clades (Fig. 1). Clade A1 is found in the centre of the Iberian Peninsula, along the Sistema Central, a mountain range that crosses the peninsula in a west-east direction. Some individuals from Clade A1 are also found in the southeastern range of the distribution of the species (Populations 64, 65 and 66, Table 1 and Fig. 1). Four individuals from Clade A1 (Pops. Lousã -13-, Góis -14-, and Guarda -15-) cluster together in a highly supported sub-clade. They correspond to the westernmost part of the distribution of Clade A1. Clade A2 occupies the northern part of the distribution. Individuals within this clade cluster in two sub-clades, roughly corresponding to a western-eastern division. Clade A3 corresponds to individuals present in the Southwest of the Iberian Peninsula, except the coastal populations from central to southern Portugal, which correspond to lineage B (see also the distribution of Clades B1-B3 below). There is also one well-supported sub-clade (Pop. Sertã, 12) that corresponds to the northernmost range of the clade. Lineage $\mathrm{B}$ is geographically restricted to coastal central and southern Portugal, and includes three clades (B1-B3, Fig. 1). Clade B1 comprises the southern Portuguese regions of Algarve, coastal Beja and Setúbal. The clade is also substructured into three subclades, one 
comprising individuals from the southernmost population of Monchique (1), the second including individuals from Arrifana and Aljezur (2,3), and the third corresponding to individuals from Cercal and Grândula $(4,5)$ (Fig. 1). Clade B2 is found in the Lisbon Peninsula, while the Clade B3 is restricted to the coastal population of Nazaré (9). There are no geographic discontinuities between mitochondrial clades. In two populations (Pinhão, 17, Sierra de San Pedro, 54) we found individuals with haplotypes included in different mitochondrial clades (A1 - A2 and A1-A3, respectively, see Fig. 1).

Phylogenetic relationships between clades are well resolved, while relationships within clades are less supported. In all the analyses carried out, clade A3 is the sister clade to Clades A1 and A2, although parsimony bootstrap values are lower than in Bayesian analyses (Fig. 1B). Clade B3 is the sister group of clades B1 and B2.

\section{Phylogeographic and historical demographic analyses:}

In Fig. 2 and Table 2, we have summarized the results of the NCA. Sequences were collapsed into 52 haplotypes, which were not connected in a single network under the statistical parsimony $95 \%$ confidence interval. They were grouped into 7 different networks. Networks I, II, III, V and VI correspond to mitochondrial Clades $\mathrm{A} 1, \mathrm{~A} 2, \mathrm{~A} 3, \mathrm{~B} 2$ and $\mathrm{B} 3$ as recovered in the phylogenetic analyses. In the NCA, Clade B1 is split into two networks, IV and IV'. The latter includes individuals from the populations of Arrifana and Aljezur $(2,3)$, whereas network IV includes samples from Monchique (1) and Cercal $(4,5)$. Network I is subdivided into two sub-networks separated by six mutational steps (Fig. 2). One includes some of the westernmost populations in Clade A2 (populations 13, 14 and 15), whereas the second includes most populations from the Spanish Sistema Central (populations 38-46 and 50-53) and the southeastern part of the range of the clade (populations 47, 49,53,54, 64-66). Network II is also subdivided into two sub-networks, without a clear geographic correspondence. Finally, Network III is subdivided into three sub-networks, one including the northern most population (12), another including populations 54-55 and a third group including populations 10-11 and 56-63.

Of the 55 clades generated in the nested design, 22 showed geographic and genetic variability and thus were tested for significant association between geographic and genetic variability with GeoDis. In most of the nested clades, the null hypothesis of no restrictions to gene flow could not be rejected. However, alternative processes were inferred for 8 clades at different nesting levels (Table 2). At most recent times (represented by lower-level clades, such as clades 1-1, 2-1, 2-4) the processes inferred correspond to restricted gene flow with isolation by distance, whereas at higher-level clades, more likely to be affected by events from a more remote past (clades 3-1, 4-2), the inference key suggests contiguous range expansions.

We found a significant relationship between geographic and genetic distances in 7 out of the 14 Mantel tests carried out, which included i) all individuals of L. boscai; ii) lineages A and B; iii) the six main clades A1-B3; iv) clades with a significant association between geographic and genetic variability recovered in the NCA. Scatter plots, correlation coefficients, and their probabilities are shown in Fig. 3. In all but one of the cases (Clade B2, $\mathrm{p}=0.039, \mathrm{r}=0.71$ ), correlation coefficients ranged from 0.10 to 0.58 . Thus we consider these correlations, although statistically significant, are weak. On the other hand, dots in the plots display a "phalange-like" or leptokurtic distribution. In most of the scatter plots we found several genetically homogeneous groups of individuals occupying relatively large ranges, 
reflecting lack of equilibrium, with gene flow being much more important than genetic drift and/or a scenario of rapid and recent colonization from genetic homogeneous population sources (Pattern II, Hutchison \& Templeton, 1999).

Historical demographic reconstructions (Bayesian Skyline plots) are shown in Fig. 4. We reconstructed the demographic history of the six clades recovered in the phylogenetic analyses. The Bayesian skyline plots depict roughly similar scenarios among clades. All clades show constant population sizes through time, a decrease in size from $150.000 \mathrm{ya}$, and more recent abrupt declines and bottlenecks $(\approx 50.000-75.000$ years), followed by rapid expansion and recovery of pre-bottleneck population sizes (Fig 4A). The more recent demographic history of L. boscai is characterized by a constant population growth for the last 40.000 years (Fig 4B).

\section{Divergence time estimates:}

Since phylogenetic relationships between and within genus of Salamandridae are not well established, we cannot confidently estimate when the lineage of Lissotriton boscai split from its sister taxon. We can, however, analyze the intraspecific temporal differentiation of the main mitochondrial clades within L. boscai in the Iberian Peninsula. Divergence time estimates are shown in Table 3. Considering the values estimated in the combined analysis, our data suggest an old split (node "s", see Fig. 1) around 5.8 Mya of the ancestral L. boscai lineage into an eastern (A, Clades A1, A2, and A3) and a western (B, Clades B1, B2, and B3) clade. The split between clades A1-A2 (Central-North) and A3 (South) took place around 1.91 Mya (node "q" in Fig 1), while A1 and A2 separated around 1.27 Mya (node "o"). In the western lineage, the split between clades B1-B2 and B3 took place around 2.58Mya (node "r"), whereas the separation of clades B1 and B2 can be dated around 1.61 Mya (node "p").

\section{Discussion}

\section{Evolutionary history of L. boscai in the Iberian Peninsula}

In an attempt to disentangle the evolutionary history of L. boscai in the Iberian Peninsula, we have analyzed the patterns of genetic variability of the species at different levels of hierarchical complexity (phylogenetic, phylogeographic, demographic). To obtain a more complete picture of the history of the species, we have attempted to date the cladogenetic events. Temporal inferences by means of molecular data, although currently rather common, are not free of controversy and drawbacks (e.g. Heads, 2005). The accuracy of the estimates relies, among other things, on the availability of external and independent data (e.g. fossil record and external calibration points for dating procedures assuming a molecular clock, or mutation rates and demographic parameters for coalescence approaches). When such data is not available, it is still valuable to estimate divergence times, although the results have to be treated with caution. Divergence time estimates should be considered as temporal hypotheses amenable to future empirical testing.

The combination of different levels of analysis has allowed us to delineate three main events in the evolutionary history of L. boscai. A first event produced a split between the A and B lineages (Fig. 1) from an ancestral population stock. The split probably occurred during the Miocene (around 5.8 Mya). This was an unexpected finding because of the apparent homogeneity of the species across its 
range. Most species with Atlantic distributions studied so far exhibit much shallower levels of genetic differentiation (see refs. above). Besides, in L. boscai the current distribution of lineages A and B is mostly continuous, although our results suggest a deep vicariant event separating the common ancestors of both lineages. The nature of this vicariant event, however, remains unclear and further research is needed.

441

In the Upper Pliocene or Lower Pleistocene (2.5-1.2 Mya), both lineages underwent further fragmentation into smaller population groups (clades A1-A3 and B1-B3). All these groupings show relatively high levels of genetic distance (ranges: $6.05-7.47 \%$ between lineages $\mathrm{A}$ and $\mathrm{B}, 1.42-3.34 \%$ between clades A1-B3, and 0.00-1.35\% within clades, uncorrected pairwise distances) and are well supported by high bootstrap values and Bayesian posterior probabilities in the phylogenetic analyses (Fig. 1). There is a strong correspondence between the recovered clades and their geographic location. Furthermore, clades A1-B3 are recovered as independent networks in the NCA analysis, and clades A1-A3 and B1 are all subdivided into two or three allopatric subclades separated by several mutation steps. Mitochondrial genetic variability in L. boscai is thus highly structured geographically. Phylogeographic processes inferred from the NCA analysis apparently involve restrictions to gene flow and isolation by distance at lower hierarchical levels of nesting. However, the isolation by distance plots shown in Fig. 3 reveal a 'phalanx'-pattern of grouping (several groups of genetically homogeneous individuals along long geographic distances). Finally, we find congruence between the Bayesian Skyline Plots (BSPs) of the six main clades within L. boscai, with contemporary bottlenecks and subsequent demographic recoveries which, keeping in mind the uncertainties associated with the confidence limits of our time estimates, might be related with onset of the last glacial maximum (23000-18000 ya) (Table 3).

Based on all available evidence, we suggest that $L$. boscai was fragmented into several (at least six) allopatric refugia during the Plio-Pleistocene. Recolonization from these refugia may have been a relatively rapid process, from genetically homogeneous population sources, and with a low incidence of long distance migrants during the recolonization process. This would conform to a "phalanx" model of range expansion, with pioneer populations advancing more or less uniformly along a wide dispersal front, thus producing wide areas of relative genetic homogeneity (Ibrahim et al. 1996). Interestingly, little intermixing between lineages has been detected, although the fact that we found haplotypes corresponding to different clades in sympatry in two locations (see above) suggests that secondary contact between clades may be more common. The relatively "old age" of the mitochondrial lineages, the highly geographically structured mitochondrial genetic variability throughout the continuous range of the species, together with the apparently low levels of introgression or admixture at the contact zones between mitochondrial lineages, make of $L$. boscai an excellent model for the analysis of historical factors and current demographic processes involved in genetic differentiation and speciation in urodeles. Finer-scale studies using more variable markers and focusing in the contact zones revealed in this study are required to confirm the extent and nature of such patterns and processes.

\section{Multiple refugia within the Iberian Peninsula}

Our results, together with previous studies, support the generality of the "refugia within refugia" scenario for the Iberian Peninsula (Gómez \& Lunt, in press). Multiple species from diverse taxonomic groups have been shown to survive the glacial ages in several allopatric Iberian refugia (Alexandrino et 
al., 2000; Branco et al., 2002; Olalde et al., 2002; Paulo et al., 2001; Vila et al., 2005). In particular, the increasing number of phylogeographic studies focused on the Iberian herpetofauna makes it possible to compare the patterns uncovered so far. Among Iberian endemics, there is a group of species with a predominantly Atlantic distribution, including the urodeles Chioglossa lusitanica and L. boscai, the anurans Discoglossus galganoi and Rana iberica as well as the lizards Podarcis bocagei and Lacerta schreiberi. Most of these have been studied from a phylogeographic perspective (Alexandrino et al., 2000, 2002; Paulo et al., 2001, 2002; Martínez-Solano, 2004, this study). These species share similar habitat requirements and dispersal abilities, and, accordingly, phylogeographic patterns exhibit a significant degree of concordance with reference to both geographical and temporal splits. Each species survived the glacial ages in several refugia, usually concentrated in or near the relicts of temperate forests during the last glacial maximum, in central and southern Portugal (Zagwijn, 1992).

Other important refugial areas for the Iberian herpetofauna were located in the surroundings of the westernmost part of the Sistema Central mountains in Central Iberia. This appears to be the case at least for L. schreiberi (Paulo et al., 2001, 2002), R. iberica (J. Teixeira, unpublished) and L. boscai (this study), although finer-scale sampling is required to test this more explicitly in other species, like D. galganoi. The patterns of genetic variability exhibited by these species (generally decreasing along a west to east axis, see references above and also Martínez-Solano et al., 2005) suggest that areas located to the east were rapidly colonized from the nearest refugia when new habitats were again available. This pattern is also evident for lineages that have colonized areas along the Cantabric coast in the northern Iberian Peninsula. Typically, populations from these areas have colonized the region from western refugia and, accordingly, they show signs of recent demographic expansion, such as lower values of genetic diversity, star-like phylogenies and/or significant results in Tajima's or Fu's neutrality tests (see discussions in Alexandrino et al., 2002, Paulo et al., 2002, and Martínez-Solano, 2004, about the cases of C. lusitanica, L. schreiberi and D. galganoi, respectively). A minor difference in the patterns observed in L. boscai is that the Central clade (Clade A1) not only successfully colonized the easternmost areas along the Sistema Central mountains, but also expanded substantially to the southeast (see Fig. 1). This inference is supported by star-like haplotype networks characterizing these populations and the results of the NCA (Fig. 2 and Table 2).

But despite these general similarities there are also important differences between species, emphasizing the importance of natural history and historical factors in shaping the evolutionary history of individual species despite the homogenizing influence of common environmental factors. First, it has already been noted that the temporal scale of genetic differentiation within $L$. boscai is much deeper to that estimated for other species. Another observation is that some species did not colonize or failed to survive in southern refugia within the Iberian Peninsula, such as C. lusitanica and R. iberica, although unfortunately crucial fossil evidence is lacking to test both hypotheses. On the other hand, for other species, such as L. boscai, the mountains near the central and southern coasts of Portugal constituted important refugial areas. More importantly, in these cases, the lineages that survived are relicts from older splitting events in the evolutionary history of these species, as in L. boscai (but see also Paulo et al., 2001 -L. schreiberi-; Martínez-Solano, 2004, D. galganoi). This pattern is also similar, although at a different scale, in the midwife toad A. cisternasii (H. Gonçalves, pers. comm.). Interestingly, this species occupies Mediterranean habitats, coexisting with L. boscai in many localities in central and southern Iberia and thus highlighting the relevance of Mediterranean-type refugia for the survival of well-differentiated clades of certain species. 


\section{Taxonomic and conservation implications}

Our data suggest that lineages A and B have had a long independent evolutionary history and they might constitute different cryptic species. Clearly, however, new data from independent sources are needed to clarify the taxonomic status of these two divergent lineages, and morphological and molecular studies including data on variation in nuclear markers will be particularly helpful in this respect. As commented above (see refs. in Introduction), variation in populations within L. boscai has been already studied from morphological and genetic perspectives, but all these previous studies have failed to include representatives of all the clades identified in our study, which can thus be used in the future as a basic framework for generating working hypotheses at progressively finer-scale levels of resolution.

L. boscai is a locally common species that, according to its wide distribution along the western half of the Iberian Peninsula has been catalogued as "Non Endangered" in Red Lists, although localized declines have been reported in populations at the easternmost limits of its distribution (Díaz Paniagua, 2002). However, our study has uncovered the existence of at least two deeply divergent lineages within L. boscai that should be managed as independent units. This is particularly important for the more geographically restricted lineage B from central and southern Portugal. Additionally, it could be argued that the independent evolutionary histories exhibited by the six main clades identified in the phylogenetic and nested clade analyses should warrant for them the status of distinct management units.

\section{Conclusions}

Our study provides a robust framework for the study of the evolutionary history of L. boscai in the Iberian Peninsula, highlighting the importance of combining analytical tools to recover the maximum amount of information contained in mt-DNA sequences at different hierarchical levels (phylogenetic, phylogeographic and historical demography analyses). The results obtained will be useful for further comparative studies involving species with similar distributions and also for more detailed studies focusing on evolutionary interactions between the identified clades. Our results also suggest that biogeographic patterns that are well studied at a continental scale (the "northern purity vs. southern richness", see Hewitt, 2001) also emerge at lower geographical scales. Thus, the comparison of phylogeographic patterns observed in the Atlantic Iberian herpetofauna shows that the higher rates of extinction are concentrated around the southernmost refugial areas, whereas the signals for recent population expansion (star-like phylogenies, significant results in neutrality tests, lower values of genetic diversity) are more common in northern areas, as would be expected under a scenario in which species tracked environmental changes with shifts in their distribution ranges rather than evolving special adaptations to new environmental conditions (see discussion in Ribera \& Vogler, 2004). Also, relict lineages from the southern refugia exhibit higher levels of genetic diversity and population fragmentation than northern lineages, which are usually more homogeneous, mirroring the patterns found at higher geographical scales. Further comparative studies using multiple molecular markers and focusing on the other southern European Peninsulas will provide insights into the generality of these patterns. 


\section{References:}

Alexandrino J, Froufe E, Arntzen JW, Ferrand N (2000). Genetic subdivision, glacial refugia and postglacial recolonization in the golden-striped salamander, Chioglossa lusitanica (Amphibia: Urodela). Molecular Ecology 9, 771-781.

Alexandrino J, Arntzen JW, Ferrand N (2002) Nested clade analysis and the genetic evidence for population expansion in the phylogeography of the golden-striped salamander, Chioglossa lusitanica (Amphibia: Urodela). Heredity 88, 66-74.

Arévalo E, Davis SK, Sites Jr. JW (1994) Mitochondrial DNA sequence divergence and phylogenetic relationships among eight chromosome races of the Sceloporus grammicus complex (Phrynosomatidae) in central Mexico. Systematic Biology 43, 387-418.

Babik W, Branicki W, Sandera M, Litvinchuk S, Borkin LJ, Irwin JT, Rafinski J (2004) Mitochondrial phylogeography of the moor frog (Rana arvalis). Molecular Ecology 13, 14691480 .

Babik W, Branicki W, Crnobrnja-Isailovic J, Cogalniceau D, Sas I, Olgun K, Poyarkov A, García-París M, Arntzen JW (2005) Phylogeography of two European newt species. Discordance between mtDNA and morphology. Molecular Ecology, 14, 2475-2491.

Branco M, Monnerot M, Ferrand N, Templeton AR (2002) Postglacial dispersal of the European rabbit (Oryctolagus cuniculus) on the Iberian Peninsula reconstructed from nested clade and mismatch analyses of mitochondrial DNA genetic variation: Evolution 56, 792-803.

Clement M, Posada D, Crandall KD (2000) TCS: a computer program to estimate gene genealogies. Molecular Ecology, 9, 1657-1659.

Deffontaine V, Libois R, Kotlik P, Sommer R, Nieberding C, Searle JB, Michaux JR (2005) Beyond the Mediterranean peninsulas: evidence of central European glacial refugia for a temperate forest mammal species, the bank vole (Clethrionomys glareolus). Molecular Ecology 14, 1727-1739.

Díaz-Paniagua C (2002). Triturus boscai. In: Atlas y libro rojo de los anfibios y reptiles de España (eds. Pleguezuelos JM, Márquez R, Lizana M), pp 61-63. Dirección General de Conservación de la Naturaleza- Asociación Herpetológica Española (2ª impresión), Madrid, Spain.

Díaz-Paniagua C, Mateo JA (1999). Geographic variation in body size and life history traits in Triturus boscai. Herpetological Journal 9, 21-27.

Drummond AJ, Rambaut A (2003) BEAST Version 1.2. URL: http//evolve.zoo.ox.ac.uk/beast.

Drummond AJ, Rambaut A, Shaphiro B, Pybus OG (2005) Bayesian coalescent inference of past population dynamics from molecular sequences. Molecular Biology and Evolution, 22, 11851192.

García-París M, Alcobendas M, Buckley D, Wake DB (2003) Dispersal of viviparity across contact zones in Iberian populations of fire salamanders (Salamandra) inferred from discordance of genetic and morphological traits. Evolution 57, 129-143

García-París M, Montori A, Herrero P (2004). Amphibia. Lissamphibia. In: Fauna Iberica. Vol. 24. (eds. Ramos Sánchez MA et al.), Museo Nacional de Ciencias Naturales, Madrid, Spain. 
610 Gómez A, Lunt DH (in press) Refugia Within Refugia: Patterns of phylogeographic concordance in the Iberian Peninsula. In: Phylogeography in Southern European Refugia: Evolutionary Perspectives on the origins and conservation of European Biodiversity (eds. Weiss S, Ferrand N). Kluwer Academic Publishers. Dordrecht, The Netherlands.

Haynes S, Jaarola M, Searle JB (2003) Phylogeography of the common vole (Microtus arvalis) with particular emphasis on the colonization of the Orkney archipelago. Molecular Ecology 12, 951956.

Heads M (2005) Dating nodes on molecular phylogenies: a critique of molecular biogeography. Cladistics 21, 62-78.

Hein J, Schierup MH, Wiuf, C (2005) Gene Genealogies, Variation and Evolution. Oxford University Press, New York, USA.

Herrero P (1991) Polytypic chromosomal variation in Triturus boscai (Urodela: Salamandridae). Génetique, Sélection et Évolution 23, 263-272.

Hewitt GM (1996) Some genetic consequences of ice ages, and their role in divergence and speciation. Biological Journal of the Linnean Society 58, 247-276.

Hewitt GM (1999) Post-glacial re-colonization of European biota. Biological Journal of the Linnean Society 68, 87-112.

Hewitt GM (2001) Speciation, hybrid zones and phylogeography or seeing genes in space and time. Molecular Ecology 10, 537-549.

Huelsenbeck JP, Ronquist F (2001) MRBAYES: Bayesian inference of phylogeny. Bioinformatics, 17 , 754-755.

Hutchinson DW, Templeton AR (1999) Correlation of pairwise genetic and geographic distance measures: inferring the relative influence of gene flow and drift on the distribution of genetic variability. Evolution 53, 1898-1914.

Ibrahim KM, Nichols RA, Hewitt GM (1996) Spatial patterns of genetic variation generated by different forms of dispersal during range expansion. Heredity 77, 282-291.

Jaarola M, Searle JB (2002) Phylogeography of field voles (Microtus agrestis) in Eurasia inferred from mitochondrial DNA sequences. Molecular Ecology 11, 2613-2621.

Larson A, Weisrock DW, Kozak KH. (2003) Phylogenetic systematics of salamanders (Amphibia: Urodela: a review). In: Reproductive Biology and Phylogeny of Urodela (ed. Sever DM). Science Publishers, Enfield, NH, USA.

Lenk P, Fritz U, Joger U, Winks M (1999) Mitochondrial phylogeography of the European pond turtle, Emys orbicularis (Linnaeus 1758). Molecular Ecology 8, 1911-1922.

Maddison DR, Maddison WP (2003) MacClade 4: Analysis of phylogeny and character evolution. Version 4.08. Sinauer Associates, Sunderland, Massachusetts.

Malkmus R (1981) Bemerkungen zu einer Triturus boscai Population in einem Brunnenbecken der Serra de Sintra. Boletim da Sociedade Portuguesa de Ciências Naturais 20, 25-40. 
Malkmus R (2004) Amphibians and Reptiles of Portugal, Madeira and the Azores Archipelago. ARG Gantner Verlag KG, Ruggell, Germany.

Mantel N (1967) The detection of disease clustering and a generalized regression approach. Cancer Research, 27, 209-220.

Martínez-Solano I (2004) Phylogeography of Iberian Discoglossus (Anura: Discoglossidae). Journal of Zoological Systematics and Evolutionary Research 42, 298-305.

Martínez-Solano I, Rey I, García-París M (2005) The impact of historical and recent factors on genetic variability in a mountain frog: the case of Rana iberica (Anura: Ranidae). Animal Conservation $8,431-441$.

Michaux JR, Libois R, Filipucci MG (2005) So close and so different: comparative phylogeography of two small mammal species, the Yellow-necked fieldmouse (Apodemus flavicollis) and the woodmouse (Apodemus sylvaticus) in the Western Palearctic region. Heredity 94, 52-63.

Nieberding C, Libois R, Douady CJ, Morand S, Michaux JR (2005) Phylogeography of a nematode (Heligmosomoides polygyrus) in the western Palearctic region: persistence of northern cryptic populations during ice ages? Molecular Ecology 14, 765-779.

Olalde M, Herran A, Espinel S, Goicoechea PG (2002) White oaks phylogeography in the Iberian Peninsula. Forest ecology and Management 156, 89-102.

Paulo OS, Dias C, Bruford MW, Jordan WC, Nichols RA (2001) The persistence of Pliocene populations through the Pleistocene climatic cycles: evidence from the phylogeography of an Iberian lizard. Proceedings of the Royal Society of London B 268, 1625-1630.

Paulo OS, Jordan WC, Bruford MW, Nichols RA (2002) Using nested clade analysis to assess the history of colonization and the persistence of populations of an Iberian lizard. Molecular Ecology $11,809-819$.

Peakall R, Smouse PE (2001) GenAlEx: Genetic Analysis in Excel. Population genetic software for teaching and research. URL:http//www.anu.edu.au/BoZo/GenAlEx.

Pfenninger M, Posada D (2002) Phylogeographic history of the land snail Candidula unifasciatas (Helicellinae, Stylommatophora): fragmentation, corridor migration, and secondary contact. Evolution, 56, 1776-1788.

Pidancier N, Miaud C, Taberlet P (2003) Premiers résultats sur la biogéographie de la Grenouille rousse Rana temporaria. Bulletin de la Société Herpétologique de France 107, 27-34.

Posada D, Crandall KD (1998) Model Test: testing the model of DNA substitution. Bioinformatics, 14, 817-818.

Posada D, Crandall KA, Templeton AR (2000) GeoDis: a program for the nested cladistic analysis of the geographic distribution of genetic haplotpes. Molecular Ecology, 9, 487-488.

Rambaut A, Drummond A (2004) TRACER. Vers. 1.1: MCMC trace analysis tool. University of Oxford. Software available via evolve.zoo.ox.ac.uk/software.html.

Ribera I, Vogler AP (2004) Speciation of Iberian diving beetles in Pleistocene refugia (Coleoptera, Dytiscidae) Molecular Ecology 13, 179-193. 
703

704

705

706

707

708

709

Rohlf RJ (1993) NTSYS-pc. Numerical Taxonomy and Multivariate Analyses System. Version 1.8. Setauket, New York, USA.

Ronquist F, Huelsenbeck JP (2003) MRBAYES 3: Bayesian phylogenetic inference under mixed models. Bioinformatics, 19, 1572-1574.

Sambrook J, Fritsch EF, Maniatis T (1989) Molecular cloning ( $2^{a} E d$.). Cold Spring Harbor Laboratory Press, New York, USA.

Schmitt T, Seitz A (2001) Allozyme variation in Polyommatus coridon (Poda, 1761) (Lepidoptera, Lycaenidae): identification of ice-age refugia and reconstruction of postglacial expansion. Journal of Biogeography 28, 1129-1136.

Sequeira F, Alexandrino J, Rocha S, Arntzen JW, Ferrand N (2005) Genetic exchange across a hybrid zone within the Iberian endemic golden-striped salamander, Chioglossa lusitanica. Molecular Ecology 14, 245-254.

Sommer RS, Benecke N (2005) The recolonization of Europe by brown bears Ursus arctos Linnaeus, 1758 after the Last Glacial Maximum. Mammal Review 35, 156-164.

Soranzo N, Alia R, Provan J, Powell W (2000) Patterns of variation at a mitochondrial sequencetagged-site locus provides new insights into the postglacial history of European Pinus sylvestris populations. Molecular Ecology 9, 1205-1211.

Stehlik I. (2003) Resistance or emigration? Response of alpine plants to the ice ages. Taxon 52, 499510.

Stewart JR, Lister AM (2001) Cryptic northern refugia and the origins of the modern biota. Trends in Ecology and Evolution 16, 608-613.

Swofford DL (2002) PAUP*. Phylogenetic Analysis Using Parsimony (*and Other Methods), version 4. Sinauer Associates, Sunderland, Masachussetts.

Taberlet P, Fumagalli L, Wust-Saucy A-G, Cossons J-F (1998) Comparative phylogeography and postglacial colonization routes in Europe. Molecular Ecology 7, 453-464.

Templeton AR (1998) Nested clade analyses of phylogeographic data: testing hypotheses about gene flow and population history. Molecular Ecology, 7, 381-397.

Templeton AR (2001) Using phylogeographic analyses of gene trees to test species status and processes. Molecular Ecology, 10, 779-791.

Templeton AR (2004) Statistical phylogeography: methods of evaluating and minimizing inference errors. Molecular Ecology 13, 789-809.

Templeton AR, Crandall KA, Sing CF (1992) A cladistic analysis of phenotypic association with haplotypes inferred from restriction endonuclease mapping and DNA sequence data. III. Cladogram estimation. Genetics 132, 619-633.

Templeton AR, Routman E, Phillips CA (1995) Separating population structure from population history: a cladistic analysis of the geographic distribution of mitochondrial DNA haplotypes in the Tiger salamander, Ambystoma tigrinum. Genetics 140, 767-782. 
Templeton AR, Sing CF (1993) A cladistic analysis of phenotypic associations with haplotypes inferred from restriction endonuclease mapping. IV. Nested analyses with cladogram uncertainty and recombination. Genetics 134, 659-669.

Vila M, Vidal-Romaní JR, Bjorklund M (2005) The importance of time scale and multiple refugia: incipient speciation and admixture of lineages in the butterfly Erebia triaria (Nymphalidae). Molecular Phylogenetics and Evolution 36, 249-260.

Weider LJ, Hobaek A, Colbourne JK, Crease TJ, Dufresne F, Hebert PDN (1999) Holarctic phylogeography of an asexual species complex I. Mitochondrial DNA variation in Arctic Daphnia. Evolution 53, 777-792.

Zagwijn WH (1992) Migration of vegetation during the Quaternary in Europe. Courier Forschungsinstitut Senckenberg 153, 9-20.

Zardoya R, Meyer A (2001) On the origin of and phylogenetic relationships among living amphibians. Proceedings of the National Academy of Sciences USA 98, 7380-7383.

\section{Acknowledgements}

E. Albert, M. Alcobendas, J. Barbadillo, C. Díaz-Paniagua, H. Gonçalves, C. Grande, M. Lapeña, R. Márquez, E. Recuero, I. Sánchez, S. Schönhuth, and I. Urbán helped in collecting samples or provided tissues. D. B. Wake and R. Pereira made useful comments and suggestions that improved the manuscript. A. Salvador and E. G. Crespo provided relevant references. The "Consejerías de Medio Ambiente" of the regions of Galicia, Asturias, Castilla-León, Madrid, Extremadura, Castilla-La Mancha and Andalucía (Spain) and ICN (Portugal) provided the legal collecting permits. This study was funded by the project CAM 07M/0090/2002 (Comunidad de Madrid, Spain, PI: MGP). IMS and DB are supported by postdoctoral fellowships from the Spanish Ministerio de Educación y Ciencia (Refs.: EX2004-0921 and EX2004-2004-0724, respectively) and JT by a PhD grant from Fundação da Ciência e Tecnologia (Ref.: BD/3376/2000). 


\section{Figure legends:}

Figure 1. (A) Distribution of L. boscai in the Iberian Peninsula (shaded), showing sampling localities (in colours). The colours represent the different lineages recovered in the phylogenetic analyses, whose putative ranges are delimited by dashed lines in the map. Numbers represent populations (see also Table 1). (B) Topology recovered in the Bayesian analysis (unpartitioned dataset: nad4+tRNA His + control region, 2.000.000 generations, burn in=2000). The topology is identical in Maximum Parsimony (MP) analyses. Also indicated are the main clades (A1-B3) discussed in the text. Numbers above branches represent Maximum Parsimony bootstrap values (100 replicates, transversion weighted three times over transitions) and \% posterior probabilities from the Bayesian analysis, respectively. Vertical lines represent the main subclades discussed in the text.

Figure 2. Nested design for the haplotype networks recovered by statistical parsimony in each of the lineages recovered in the phylogenetic analyses.

Figure 3. Isolation by Distance plots, showing the relationship between geographic (x axis, in $\mathrm{km}$ ) and genetic distances (y axis, ML-corrected distance) between samples. Only significant results for the Mantel tests are shown $(\mathrm{p}<0.05)$. The correlation coefficient $(\mathrm{r})$ determines the "strength" of the correlation between matrices (see the text for a detailed discussion).

Figure 4. Bayesian Skyline Plots (BSP). Historical demographic trends of mitochondrial lineages in $L$. boscai are represented; $\mathbf{x}$ axis: time in $10^{6}$ years before present; $\mathbf{y}$ axis: estimated population size [units $=\mathrm{N}_{\mathrm{e}} \tau$, the product of effective population size and generation length in years (log transformed)]. BSPs for clades A1, A2, A3, B1 and B2 show similar profiles (A), with bottleneck events around 40.00075.000 years ago, and subsequent rapid recoveries of population sizes. When calculated for the most recent clades of the phylogenetic tree (i.e., demographic trends within clades), BSPs show continuous population growth for the last 50.000 years $(\mathbf{B})$. 
Table 1. Sampling localities, population identifiers (ID), sample size (n) and GenBank accession numbers for the sequences obtained for this study (to be added upon manuscript acceptance).

1 Portugal: Monchique

2 Portugal: Arrifana, Alzejur

3 Portugal: Zambujeira de Baixo, Aljezur

4 Portugal: Barqueiros, Odemira
Portugal: Santa Margarida da Serra, Grândula

Portugal: Sintra

Portugal: S. Bartolomeu dos Galegos, Lourinhã

Portugal: Alcanena, Alcobaça

Portugal: Valado dos Frades, Nazaré

Portugal: Azaruja, Évora

Portugal: Castelo de Vide

Portugal: Cernache de Bonjardim, Sertã

Portugal: Lousã

Portugal: Góis

Portugal: Famalicão, Guarda

Portugal: São Pedro do Sul

Portugal: Pinhão

Portugal: Mogadouro

Portugal: Chaves

Portugal: Cabeceiras de Basto

Portugal: Alfena, Valongo

Portugal: Vila Nova de Cerveira

Portugal: Carris, Terras de Bouro

Spain: A Pobra do Caramiñal, A Coruña

Spain: Abelleira, A Coruña

Spain: Noceda, Pontevedra

Spain: Alto da Ermida, Ourense

Spain: Alfonxe, Lugo

Spain: Villacondide, Asturias

Spain: Esqueiro, Asturias

Spain: Carracedelo, León

Spain: Destriana, León

Spain: Sanabria, Zamora

Spain: Lubián, Zamora

Spain: Sarracín de Aliste, Zamora

Spain: Tábara, Zamora

Spain: Saelices el Chico, Salamanca

Spain: Miranda del Castañar, Salamanca

\section{nad4 control region}

$* * * * * * * *_{\text {_ }} * * * * * * * * * * * * * * * * *_{*} * * * * * * * * *$

$* * * * * * * *_{-} * * * * * * * * * * * * * * * *_{*} * * * * * * * * *$

$* * * * * * * *_{-} * * * * * * * * * * * * * * * *_{-} * * * * * * * *$

$* * * * * * * *_{-} * * * * * * * * * * * * * * * *_{*} * * * * * * * *$

$* * * * * * * *_{-} * * * * * * * * * * * * * * * *_{-} * * * * * * * *$

$* * * * * * * *_{-} * * * * * * * * * * * * * * * * *_{-} * * * * * * * *$

$* * * * * * * *_{-} * * * * * * * * * * * * * * * *_{*} * * * * * * * * *$

$* * * * * * * *_{-} * * * * * * * * * * * * * * * * *_{-} * * * * * * * *$

$* * * * * * * *$ *******************;*********

$* * * * * * * *$ *****************************

$* * * * * * * *_{-} * * * * * * * * * * * * * * * *_{*} * * * * * * * *$

$* * * * * * * *_{-} * * * * * * * * * * * * * * * *_{*} * * * * * * * * *$

$* * * * * * * *_{-} * * * * * * * * *_{*} * * * * * * *_{-} * * * * * * * *$

*********_********* **********_*********

$* * * * * * * *_{-} * * * * * * * * * * * * * * * *_{-} * * * * * * * *$

$* * * * * * * *_{-} * * * * * * * * * * * * * * * *_{-} * * * * * * * *$

$* * * * * * * *_{-} * * * * * * * * * * * * * * * *_{-} * * * * * * * *$

$* * * * * * * *_{-} * * * * * * * * * * * * * * * * *_{-} * * * * * * * *$

$* * * * * * * *_{-} * * * * * * * * * * * * * * * *_{-} * * * * * * * *$

*********_******************_********

$* * * * * * * *_{-} * * * * * * * * * * * * * * * * *_{-} * * * * * * * *$

$* * * * * * * *_{-} * * * * * * * * * * * * * * * *_{-} * * * * * * * *$

$* * * * * * * *_{-} * * * * * * * * * * * * * * * *_{*} *_{*} * * * * * * *$

$* * * * * * * *_{-} * * * * * * * * * * * * * * * *_{*} * * * * * * * *$

$* * * * * * * *_{-} * * * * * * * * *_{*} * * * * * * *_{-} * * * * * * * *$

$* * * * * * * *_{-} * * * * * * * * * * * * * * * * *_{-} * * * * * * * *$

$* * * * * * * *_{-} * * * * * * * * * * * * * * * *_{*} * * * * * * * * *$

*********_********* *********_*********

$* * * * * * * *_{-} * * * * * * * * * * * * * * * *_{-} * * * * * * * *$

*********_******************_********

$* * * * * * * *_{-} * * * * * * * * * * * * * * * *_{-} * * * * * * * *$

$* * * * * * * *_{-} * * * * * * * * * * * * * * * *_{*} * * * * * * * * *$

$* * * * * * * *_{-} * * * * * * * * * * * * * * * *_{-} * * * * * * * *$

$* * * * * * * *$ ********************_*********

$* * * * * * * *$ * $* * * * * * * * * * * * * * * *_{-} * * * * * * * * *$

$* * * * * * * *$ ******************************

$* * * * * * * *_{-} * * * * * * * * * * * * * * * *_{2} * * * * * * * *$

$* * * * * * * *_{-} * * * * * * * * * * * * * * * *_{-} * * * * * * * *$ 


\begin{tabular}{|c|c|c|c|}
\hline 39 & Spain: Navatalgordo, Ávila & 1 & $* * * * * * * *_{-} * * * * * * * * * * * * * * * *_{-} * * * * * * * *$ \\
\hline 40 & Spain: Navas del Marqués, Ávila & 2 & $* * * * * * * * *_{-} * * * * * * * * * * * * * * * * *_{-} * * * * * * * *$ \\
\hline 41 & Spain: Robledo de Chavela, Madrid & 2 & $* * * * * * * *_{-} * * * * * * * * * * * * * * * *_{-} * * * * * * * *$ \\
\hline 42 & Spain: Navas del Rey, Madrid & 1 & $* * * * * * * *_{-} * * * * * * * * * * * * * * * *_{-} * * * * * * * * *$ \\
\hline 43 & Spain: Navalagamella, Madrid & 1 & $* * * * * * * *_{-} * * * * * * * * * * * * * * * *_{-} * * * * * * * *$ \\
\hline 44 & Spain: Guadarrama, Madrid & 2 & $* * * * * * * *_{-} * * * * * * * * * * * * * * * *_{-} * * * * * * * *$ \\
\hline 45 & Spain: Sierra de la Higuera, Madrid & 1 & $* * * * * * * *_{-} * * * * * * * * * * * * * * * *_{-} * * * * * * * *$ \\
\hline 46 & Spain: El Real de San Vicente, Toledo & 1 & $* * * * * * * * *_{-} * * * * * * * * * * * * * * * * *_{-} * * * * * * * *$ \\
\hline 47 & Spain: San Pablo de los Montes, Toledo & 1 & $* * * * * * * *_{-} * * * * * * * * * * * * * * * * *_{-}+* * * * * * * *$ \\
\hline 49 & Spain: Garciaz, Cáceres & 1 & $* * * * * * * * *_{-} * * * * * * * * * * * * * * * * *_{-} * * * * * * * *$ \\
\hline 48 & Spain: Garganta la Olla, Cáceres & 2 & $* * * * * * * *_{-} * * * * * * * * * * * * * * * *_{-} * * * * * * * *$ \\
\hline 50 & Spain: Valverde del Fresno, Cáceres & 1 & $* * * * * * * *_{-} * * * * * * * * * * * * * * * *_{-} * * * * * * * *$ \\
\hline 51 & Spain: Acebo, Cáceres & 2 & $* * * * * * * * *_{-} * * * * * * * * * * * * * * * * * *_{-} * * * * * * * *$ \\
\hline 52 & Spain: Gata, Cáceres & 2 & $* * * * * * * *$ * $* * * * * * * * * * * * * * * * * *_{-} * * * * * * * *$ \\
\hline 53 & Spain: Villasbuenas de Gata, Cáceres & 2 & $* * * * * * * *_{-} * * * * * * * * * * * * * * * * *_{-} * * * * * * * * *$ \\
\hline 54 & Spain: Montánchez, Cáceres & 2 & $* * * * * * * * *_{-} * * * * * * * * * * * * * * * * *_{-} * * * * * * * *$ \\
\hline 55 & Spain: Villar del Rey, Badajoz & 2 & $* * * * * * * *_{-} * * * * * * * * * * * * * * * * *_{-}+* * * * * * * *$ \\
\hline 56 & Spain: Pallares, Badajoz & 1 & $* * * * * * * * *_{-} * * * * * * * * * * * * * * * *_{-} * * * * * * * *$ \\
\hline 57 & Spain: Fuentes de León, Badajoz & 1 & $* * * * * * * * *_{-} * * * * * * * * * * * * * * * * *_{-} * * * * * * * *$ \\
\hline 58 & Spain: Cortelazor, Huelva & 2 & $* * * * * * * * *_{-} * * * * * * * * * * * * * * * *_{-} * * * * * * * *$ \\
\hline 59 & Spain: Linares de la Sierra, Huelva & 1 & $* * * * * * * * *_{-} * * * * * * * * * * * * * * * *_{-} * * * * * * * *$ \\
\hline 60 & Spain: Calañas, Huelva & 1 & $* * * * * * * * *_{-} * * * * * * * * * * * * * * * * *_{-} * * * * * * * *$ \\
\hline 61 & Spain: Doñana, Sevilla & 4 & $* * * * * * * *_{-} * * * * * * * * * * * * * * * * *_{-} * * * * * * * *$ \\
\hline 62 & Spain: El Pedroso, Sevilla & 2 & $* * * * * * * * *_{-} * * * * * * * * * * * * * * * *_{-} * * * * * * * *$ \\
\hline 63 & Spain: Constantina, Sevilla & 1 & $* * * * * * * * *_{-} * * * * * * * * * * * * * * * * *_{-} * * * * * * * *$ \\
\hline 64 & Spain: Almadén, Ciudad Real & 2 & $* * * * * * * *_{-} * * * * * * * * * * * * * * * *_{-} * * * * * * * *$ \\
\hline 65 & Spain: Villanueva de Córdoba, Córdoba & 1 & $* * * * * * * *_{-} * * * * * * * * * * * * * * * *_{-} * * * * * * * *$ \\
\hline 66 & Spain: Venta del Charco, Córdoba & 1 & $* * * * * * * * *_{-} * * * * * * * * * * * * * * * * *_{-} * * * * * * * *$ \\
\hline
\end{tabular}

Total: 103 
Table 2. Results of the Nested Clade Analysis (NCA), indicating the inference chain for each clade 784 showing significant associations between geographic and genetic structure and the processes inferred 785 by the latest version of the GeoDis inference key.

\section{Clade Inference chain Inferred processes}

$1-1 \quad 1-2-3-4$

Restricted gene flow with isolation by distance

$1-4 \quad 1-2-11-12-13-14$

Contiguous range expansion or

Long distance colonization or

Past fragmentation

$2-1 \quad 1-2-3-4$

Restricted gene flow with isolation by distance

$2-4 \quad 1-2-3-4$

Restricted gene flow with isolation by distance

3-1 1-2-11-12

Contiguous range expansion

4-1 No I-T distance

Inconclusive outcome

4-2 19-20-2-11-12

Contiguous range expansion

4-3 No I-T distance

Inconclusive outcome 
Table 3. Divergence time estimates [in millions of years (Mya)] in mitochondrial lineages within $L$. 791 boscai for every node recovered in the phylogenetic analyses (see Fig. 1). Cladogenetic events were 792 dated according to a Molecular Clock and to a Bayesian-coalescence based approaches. We present 793 mean values (boldfaced) and 95\% Confidence Intervals (C.I.) for each estimate. In the coalescence 794 795 approach, divergence times were calculated under the assumption of three different mutation rates: 0.01 mutations/site/Mya ( $=2 \%$ pairwise sequence divergence); 0.008 mutations/site/Mya $(=1.6 \%$ pairwise sequence divergence); and 0.006 mutations $/$ site/Mya $(=1.2 \%$ pairwise sequence divergence). In addition, we also estimated the mean values and C.I. in a combined analysis of the three previous analyses with the program Tracer 1.3 (see text for further details).

\begin{tabular}{|c|c|c|c|c|c|}
\hline NODE & Molecular Clock & $2,0 \%$ & $1,6 \%$ & $1,2 \%$ & COMBINED \\
\hline $\begin{array}{c}\mathbf{a} \\
95 \% \mathrm{CI}\end{array}$ & 0,11 & $\begin{array}{c}\mathbf{0 , 1 0} \\
0.038-0.193\end{array}$ & $\begin{array}{c}\mathbf{0 , 1 2} \\
0.05-0.229\end{array}$ & $\begin{array}{c}\mathbf{0 , 1 7} \\
0.077-0.301\end{array}$ & $\begin{array}{c}\mathbf{0 , 1 3} \\
0.041-0.252\end{array}$ \\
\hline $\begin{array}{c}\mathbf{b} \\
95 \% \mathrm{CI}\end{array}$ & 0,22 & $\begin{array}{c}\mathbf{0 , 1 3} \\
0.031-0.261\end{array}$ & $\begin{array}{c}\mathbf{0 , 1 6} \\
0.035-0.319\end{array}$ & $\begin{array}{c}\mathbf{0 , 2 2} \\
0.504-0.432\end{array}$ & $\begin{array}{c}\mathbf{0 , 1 7} \\
0.033-0.357\end{array}$ \\
\hline $\begin{array}{c}\mathbf{c} \\
95 \% \mathrm{CI}\end{array}$ & 0,11 & $\begin{array}{c}\mathbf{0 , 0 7} \\
0.027-0.138\end{array}$ & $\begin{array}{c}\mathbf{0 , 0 9} \\
0.036-0.166\end{array}$ & $\begin{array}{c}\mathbf{0 , 1 3} \\
0.036-0.233\end{array}$ & $\begin{array}{c}\mathbf{0 , 1 0} \\
0.027-0.191\end{array}$ \\
\hline $\begin{array}{c}\text { d } \\
95 \% \mathrm{CI}\end{array}$ & 0,11 & $\begin{array}{c}\mathbf{0 , 0 7} \\
0.026-0.131\end{array}$ & $\begin{array}{c}\mathbf{0 , 0 8} \\
0.030-0.153\end{array}$ & $\begin{array}{c}\mathbf{0 , 1 1} \\
0.034-0.208\end{array}$ & $\begin{array}{c}\mathbf{0 , 0 9} \\
0.030-0.173\end{array}$ \\
\hline $\begin{array}{c}\mathbf{e} \\
95 \% \mathrm{CI}\end{array}$ & 0,11 & $\begin{array}{c}\mathbf{0 , 0 8} \\
0.089-0.184\end{array}$ & $\begin{array}{c}\mathbf{0 , 1 0} \\
0.012-0.235\end{array}$ & $\begin{array}{c}\mathbf{0 , 1 2} \\
0.019-0.302\end{array}$ & $\begin{array}{c}\mathbf{0 , 1 0} \\
0.011-0.246\end{array}$ \\
\hline $\begin{array}{c}\mathbf{f} \\
95 \% \mathrm{CI}\end{array}$ & 0,44 & $\begin{array}{c}\mathbf{0 , 3 1} \\
0.133-0.510\end{array}$ & $\begin{array}{c}\mathbf{0 , 3 9} \\
0.168-0.640\end{array}$ & $\begin{array}{c}\mathbf{0 , 5 1} \\
0.188-0.840\end{array}$ & $\begin{array}{c}\mathbf{0 , 4 0} \\
0.143-0.718\end{array}$ \\
\hline$\underset{95 \% \mathrm{CI}}{\mathbf{g}}$ & 0,55 & $\begin{array}{c}\mathbf{0 , 4 3} \\
0.223-0.695\end{array}$ & $\begin{array}{c}\mathbf{0 , 5 5} \\
0.268-0.881\end{array}$ & $\begin{array}{c}\mathbf{0 , 7 3} \\
0.367-1.161\end{array}$ & $\begin{array}{c}\mathbf{0 , 5 7} \\
0.218-0.984\end{array}$ \\
\hline $\begin{array}{c}\mathbf{h} \\
95 \% \mathrm{CI}\end{array}$ & 0,02 & $\begin{array}{c}\mathbf{0 , 0 2} \\
0.0007-0.048\end{array}$ & $\begin{array}{c}\mathbf{0 , 0 3} \\
0.0007-0.058\end{array}$ & $\begin{array}{c}\mathbf{0 , 0 3} \\
0.0007-0.082\end{array}$ & $\begin{array}{c}\mathbf{0 , 0 3} \\
0.0007-0.0068\end{array}$ \\
\hline $\begin{array}{c}\text { I } \\
95 \% \mathrm{CI}\end{array}$ & 0,44 & $\begin{array}{c}\mathbf{0 , 4 1} \\
0.185-0.632\end{array}$ & $\begin{array}{c}\mathbf{0 , 5 1} \\
0.233-0.803\end{array}$ & $\begin{array}{c}\mathbf{0 , 6 8} \\
0.324-1.088\end{array}$ & $\begin{array}{c}\mathbf{0 , 5 3} \\
0.208-0.931\end{array}$ \\
\hline$\stackrel{\mathbf{j}}{95 \% \mathrm{CI}}$ & 0,44 & $\begin{array}{c}\mathbf{0 , 4 0} \\
0.201-0.632\end{array}$ & $\begin{array}{c}\mathbf{0 , 5 0} \\
0.251-0.791\end{array}$ & $\begin{array}{c}\mathbf{0 , 6 9} \\
0.347-1.095\end{array}$ & $\begin{array}{c}\mathbf{0 , 6 9} \\
0.209-0.924\end{array}$ \\
\hline
\end{tabular}




\begin{tabular}{|c|c|c|c|c|c|}
\hline $\mathbf{k}$ & 0,55 & 0,54 & 0,67 & 0,89 & 0,70 \\
\hline $95 \% \mathrm{CI}$ & & $0.284-0.828$ & $0.347-0.991$ & $0.466-1.381$ & $0.313-1.193$ \\
\hline 1 & 0,65 & 0,63 & 0,78 & 1,05 & 0,82 \\
\hline $95 \% \mathrm{CI}$ & & $0.362-0.936$ & $0.447-1.163$ & $0.591-1.54$ & $0.375-1.334$ \\
\hline $\mathbf{m}$ & 0,33 & 0,28 & 0,35 & 0,47 & 0,37 \\
\hline $95 \% \mathrm{CI}$ & & 0.099-0.472 & $0.113-0.602$ & $0.173-0.822$ & $0.110-0.682$ \\
\hline $\mathbf{n}$ & 0,11 & 0,05 & 0,08 & 0,10 & 0,08 \\
\hline $95 \% \mathrm{CI}$ & & $0.01-0.126$ & $0.016-0.175$ & $0.020-0.213$ & $0.011-0.177$ \\
\hline $\mathbf{0}$ & 0,93 & 0,96 & 1,21 & 1,64 & 1,27 \\
\hline $95 \% \mathrm{CI}$ & & $0.606-1.342$ & $0.759-1.672$ & $1.039-2.281$ & $0.666-2.052$ \\
\hline $\mathbf{p}$ & 1,36 & 1,23 & 1,54 & 2,06 & 1,61 \\
\hline $95 \% \mathrm{CI}$ & & 0.798-1.702 & $1.005-2.130$ & $1.295-2.815$ & $0.854-2.513$ \\
\hline $\mathbf{q}$ & 1,31 & 1,46 & 1,83 & 2,46 & 1,91 \\
\hline $95 \% \mathrm{CI}$ & & 0.970-1.988 & $1.259-2.509$ & $1.63-3.333$ & $1.049-2.987$ \\
\hline $\mathbf{r}$ & 1,75 & 1,97 & 2,47 & 3,29 & 2,58 \\
\hline $95 \%$ CI & & $1.348-2.746$ & $1.66-3.404$ & $2.21-4.543$ & $1.415-4.031$ \\
\hline $\mathbf{s}$ & 4,36 & 4,41 & 5,57 & 7,39 & 5,79 \\
\hline $95 \% \mathrm{CI}$ & & $3.117-5.88$ & $3.931-7.508$ & $5.277-9.837$ & $3.322-8.845$ \\
\hline $\mathbf{t}$ & 18,76 & 15,47 & 19,38 & 25,58 & 20,14 \\
\hline $95 \% \mathrm{CI}$ & & $9.871-21.346$ & $12.323-26-534$ & $16.41-33.914$ & $10.897-31.392$ \\
\hline
\end{tabular}

800

801 (Table 3, continued)

802 


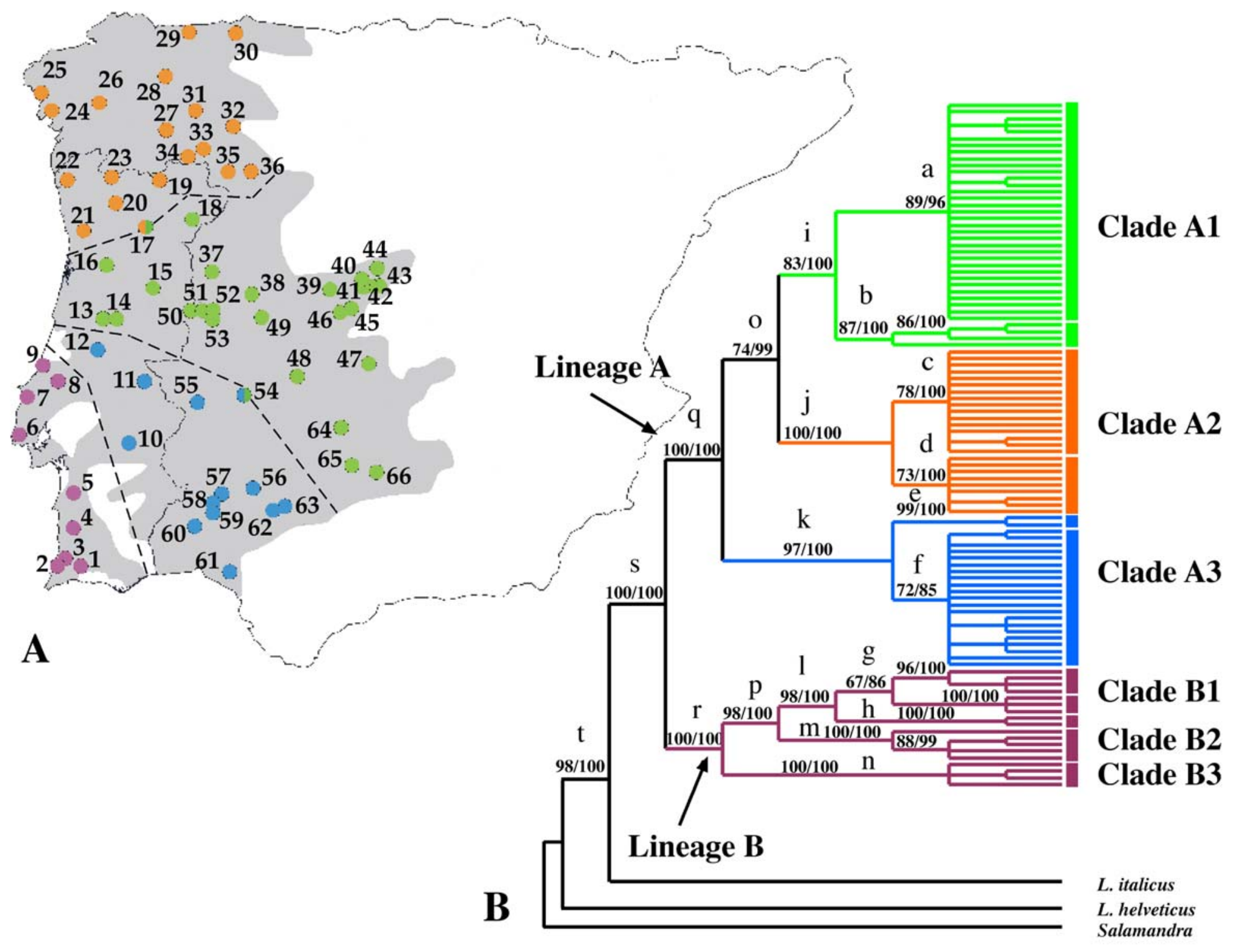

Figure 1. 


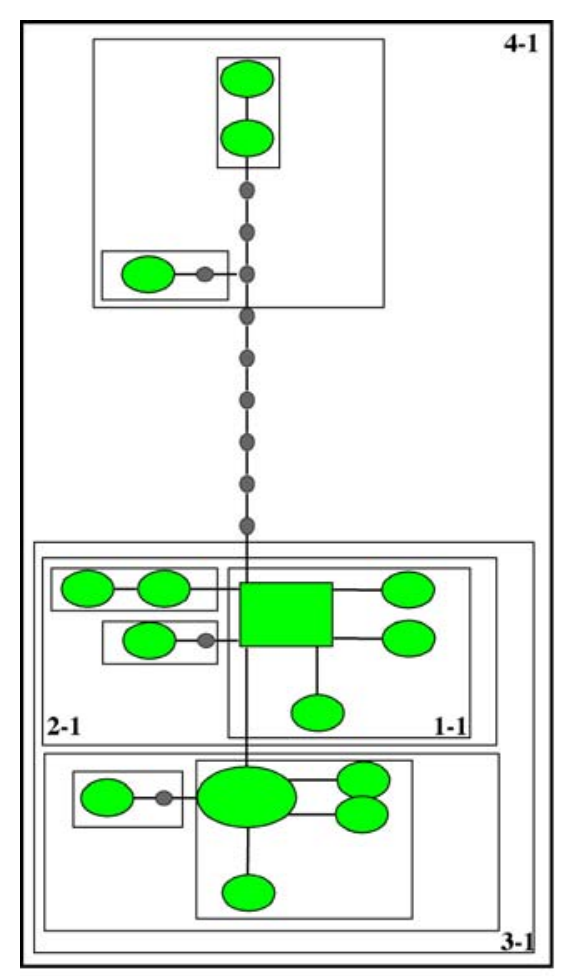

Network I

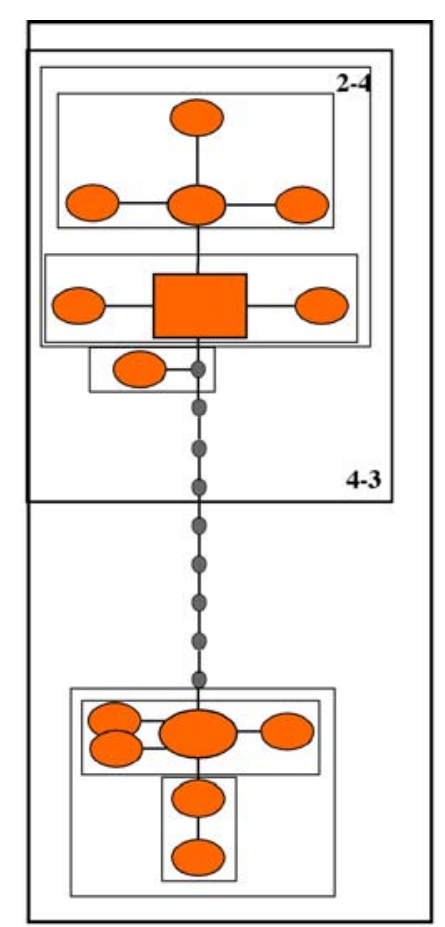

Network II

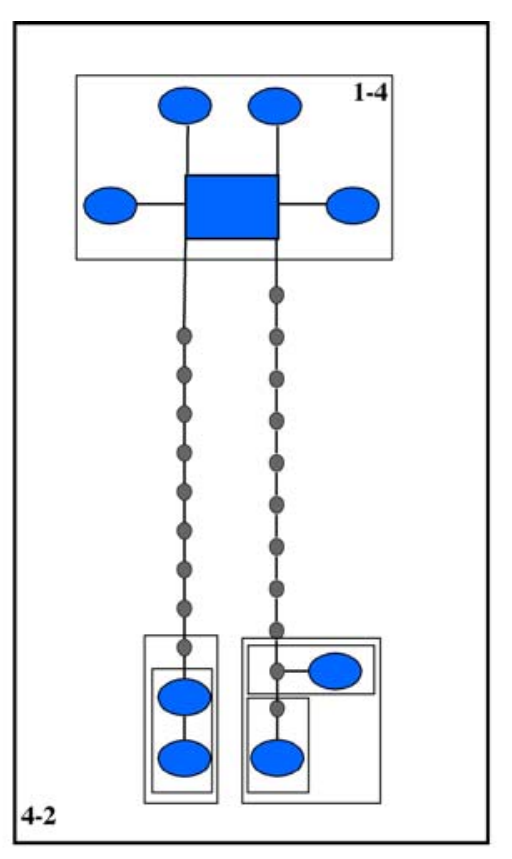

Network III

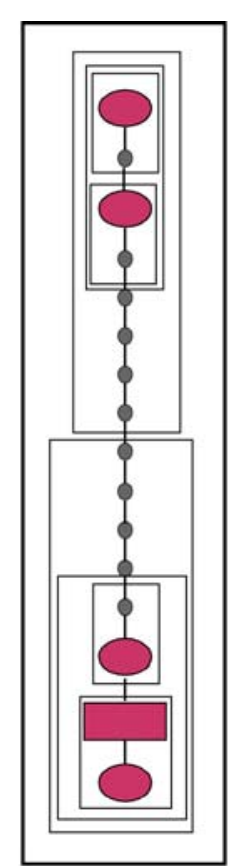

Network IV

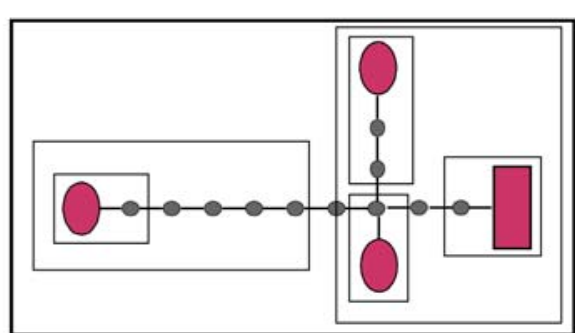

Network V

Figure 2. 

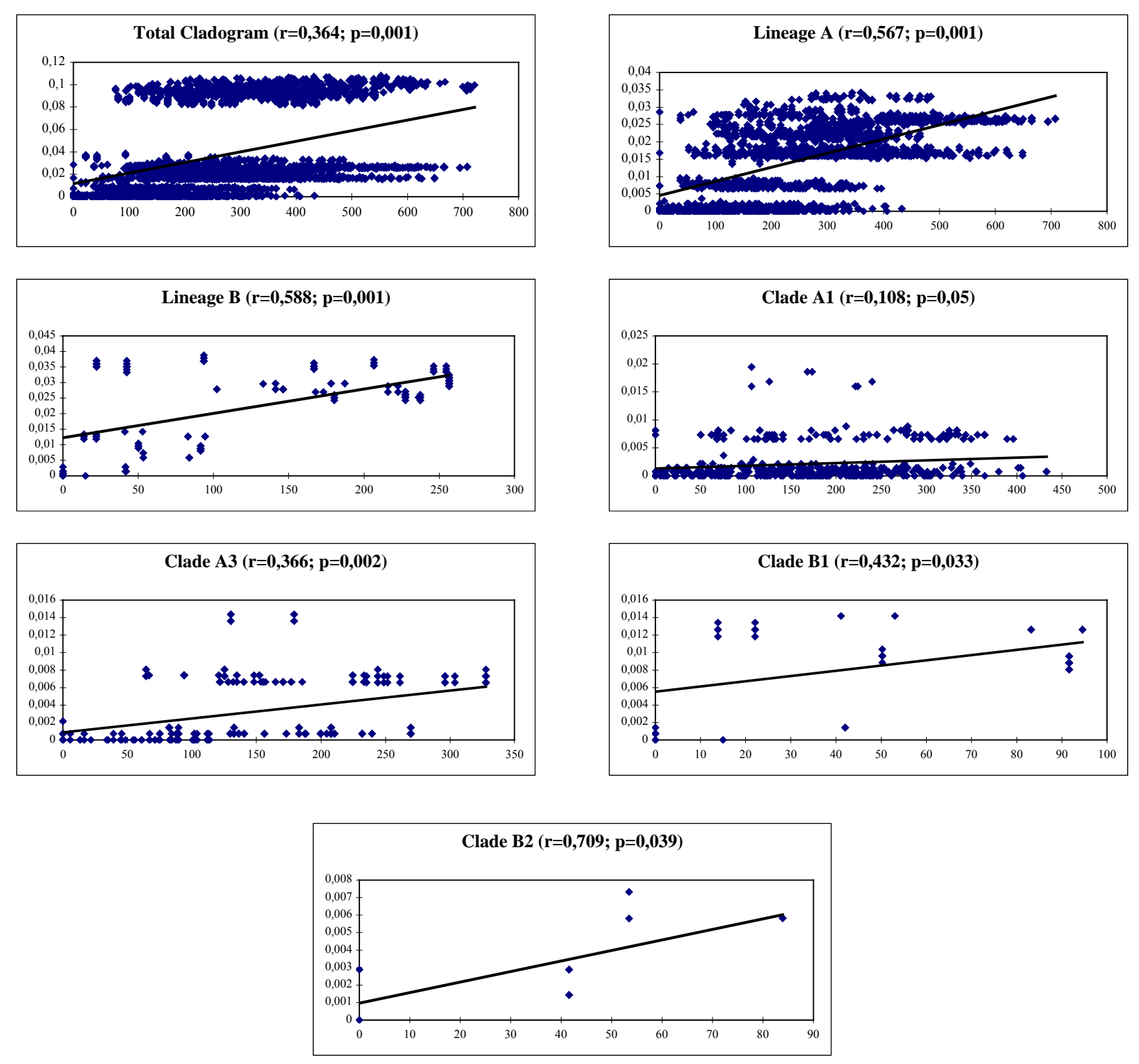

Figure 3. 


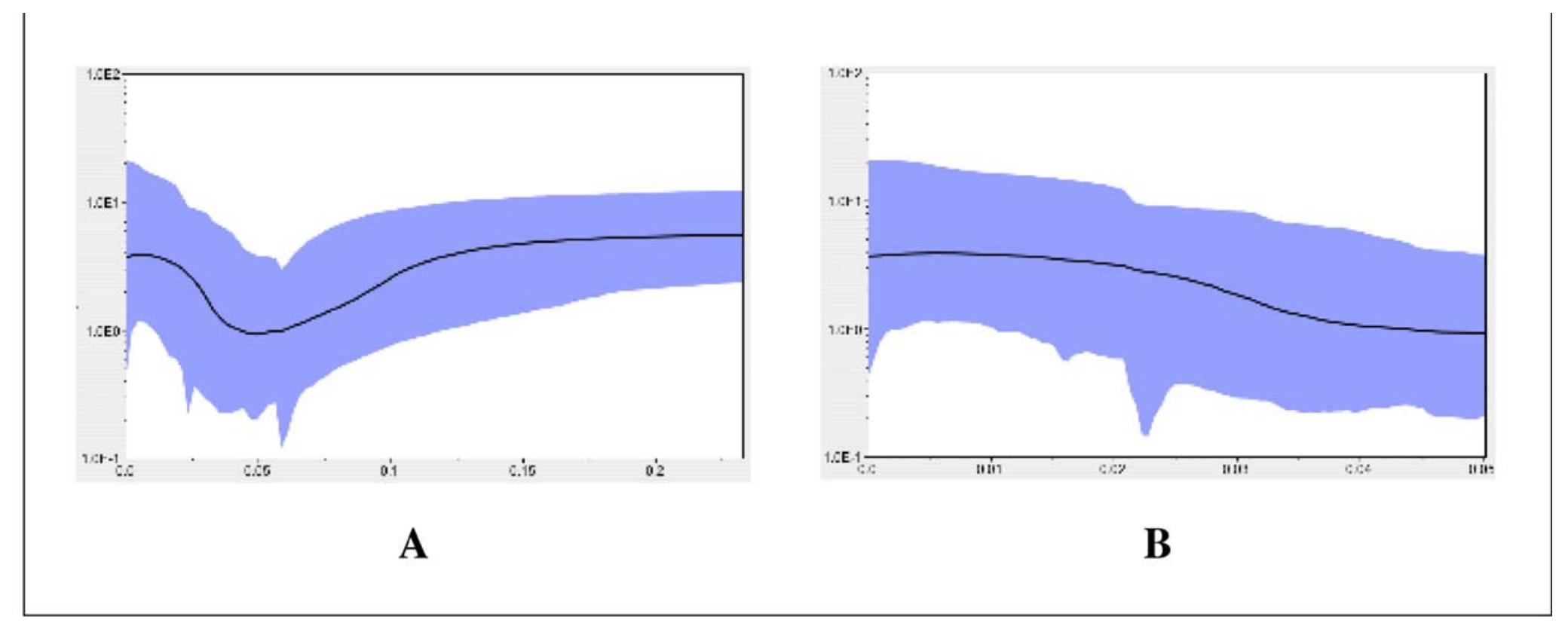

Figure 4. 